\title{
Violence against Preparatory School Teachers at Cairo Governorate
}

\author{
Eman M. Seif El-Nasr \\ Lecturer of Community Health Nursing, Faculty of Nursing, Cairo University
}

\begin{abstract}
Higher rates of violence directed toward teachers were associated with disorganized school structures, negative school climates, lack of administrative and collegial social supports, and high residential crowding. Aim: to assess frequency and causes of school violence against school teachers and develop a guideline to prevent school violence against teachers. Design: a descriptive correlational research design was utilized. Setting: data were collected from preparatory schools for boys at EL-Sayeda Zeinab educational directorate. Sample: a convenient sample of all teachers in preparatory schools for boys at EL-Sayeda Zeinab educational directorate who exposed to violence was included in the study. Tool for data collection: one tool was used in this study; School teacher structured interviewing Sheet that has two parts: 1) teacher's personal and work data: age, sex, educational level, job category and duration of work. 2) Violence data: types of violence, source of violence, frequency of exposure to violence and occurrence of injury, causes of school violence and work environment. Results: study results revealed that, $76.3 \%$ of the teachers were males, their mean age was $39.79 \pm 6.9$ year and all the teachers were married. Regarding mean work duration it was $13.92 \pm 6.97$ year. Results revealed that, $52.6 \%$ of teachers were exposed to verbal violence and $38.2 \%$ of them were exposed to both physical and verbal violence. In relation to the frequency of violence, $67.1 \%$ of teachers were exposed to violence less than five times while $32.9 \%$ reported exposure to violence five times. Regarding the sources of violence, $64.9 \%$ of the teachers were exposed to violent acts by students and $19.7 \%$ of them were exposed to violence from student's parents. Only $13.6 \%$ of teachers reported exposure to physical injury and $33.8 \%$ officially reported after exposure to violence. As for the causes of violence results revealed that, $87.3 \%$ of the students developed a violent behavior probably as a result of overcrowded classes, $95.2 \%$ as a result of large family size and $82 \%$ absence of trained security person in the schools. Conclusion: the common causes of violence were; overcrowded classes, large family size, and absence of trained security person. Recommendations: based on the study results the following recommendations were suggested; this study should be carried out on a large sample of teachers and student's perspectives on violence against teachers.
\end{abstract}

Keywords: school violence, school teachers, preventive guidelines.

\section{Introduction}

School violence is a serious problem, especially in public schools that increasingly affects students and teachers at all academic levels. Whereas teachers are perpetrators, they may become victims for school violence because they are faced with number of challenges as; diverse students not only in terms of cultural backgrounds, but also in terms of academic, behavioral, and social skill [1].

School violence is any deliberate act that harms or threatens to harm a student, teacher or other school officials and interferes with the purpose of school [2]. Violence has many forms according to the definitions of the World Health Organization (WHO) including physical assault, verbal abuse, bullying/ mobbing, sexual harassment and psychological stress. National Institute of Occupational Safety and Health (NIOSH) defined workplace violence as violent act including physical assaults directed toward a person at work or duty [3]. Violence against teachers is present in countries of different cultures around the world, but not equally distributed. The most common type of violence from students to teacher is verbal but physical violence is rarer [4].

School-based violence is a public health problem that has received growing national attention. According to report done by the United States Bureau of Justice statistics, during the 2011-2012 school years, a high percent of governmental than private school teachers reported that, they were threatened with injury or being physically attacked by a student from their school [3]. School-based violence against teachers has a negative impact not only on teachers, but on students and school systems as well. As teacher victimization may result in lost wages, lost instructional time/productivity, increase compensation payments, litigation costs, negative publicity for the school, and negative student behavioral and academic outcomes [1].

Traditional forms of violence against teachers include; physical, verbal and social. Physical violence is defined as deliberate, repeated or one-time infliction of pain and/ or body injuries by another that involves potential risk of harm and consequences of which may or may not be visible. While verbal violence is the most common form

DOI: 10.9790/1959-0602024249 $\quad$ www.iosrjournals.org $\quad 42 \mid$ Page


and defined as use of inappropriate and harsh words to hurt another person. Students and sometimes their parents use verbal violence to express their discontent. Regarding social violence, it includes saying untruths about the teacher in order to undermine his/her dignity. It is expressed by ignoring, avoiding, gossiping, refusing collaboration and sabotaging teacher's work [4]. Recently modern form of violence is electronic violence defined as intentional of pain and injury that may damage the reputation, status and dignity of the teacher by using electronic devices as mobile phones, internet and popular social network [5].

Researches explained that, the possible causes of students' violent behavior against their teachers include, neglecting moral values and moral education in general, especially when it comes to respect what is considered oldfashioned, movies, video and computer games. Some of family causes that encourage violent behavior are: dysfunctional families that do not develop child's empathy, due to a lack of commitment of family members, a sense of inferiority and resentment can occur, so the student wants to stand out and dominate outside it. So, family needs to raise student by conveying to them correct moral views that can be applied in their life later. In case it does not, student become self- centered, do not accept anyone's authority, expect that everything should adapt to them and behave violently in order to achieve their intentions [6].

Teachers can affect students' reactions with their way of working through well preparation of materials, interesting content presentation and good communication with specifically boundaries of acceptable behavior, together with the teacher being an example through creating a proper working atmosphere that will help in the prevention of undesirable student's behavior. The effects of school violence against teacher are suffering from negative developmental outcomes, decreasing in academic achievement, less supportive interpersonal relationships, and withdrawal, as well as negative social behavior, coping mechanisms and social functioning [7].

In a study conducted in Finland, it revealed that $32.6 \%$ of teachers have experienced violence either every week, or almost every day while $67.4 \%$ reported that they have never experienced violence from students [1]. Another study conducted in Brazil indicated that, $11 \%$ of public school principals reported that students were engaged in violence on a daily or weekly basis, $6 \%$ reported students engaging in verbal abuse directed toward their teachers, $7 \%$ of teachers reported being threatened with injury by a student at their school and $4 \%$ reported being physically attacked, these reports of threat and injury were high in urban schools, public schools and among male teachers [8].

School nurses have a key role in preventing and reducing violence in the school setting on several levels, as outlined in a position statement by the National Association of School Nurses (NASN) [9]. First, school nurses act to create safe school environments by collaborating with school personnel, parents, healthcare providers, and community members. They promote evidenced-based education and programs related to violence prevention. The nurse also identifies physical symptoms that may be caused by effects of violence, such as headaches, stomach aches, and injuries. With this knowledge, the nurse can intervene and make appropriate referrals [10].

School health nurse has ultimate goal for prevention of violence and the safety for staff and the school community as a whole. This involves providing education to the school community in problem solving and conflict resolution skills, recognizing early warning signs that lead to violence and factors outside of the school setting that might predispose to violent behavior. Also school health nurse are able to support the efforts of administration to provide and maintain security; to offer programs to parents that support building skills in the areas of communication, problem solving, monitoring of their children and assist in the development of school discipline policy. School health nurses are also able to serve on school safety and curriculum committees, identifying, advocating and implementing prevention programs within the school community. When violence occurs, they are positioned to intervene, working collaboratively to change the dynamics of the crisis situation [11].

There are many factors which contribute to the onset of school violence and develop a violent attitude in children especially in Egypt. The lifestyle and standard of living is so sophisticated that parents have very little time for their children and most of the children are neglected by parents. Circle of friends contributes greatly to violent behavior on a large extent. If the student spends most of his time with a gang of friends who are naughty, haughty and arrogant then he will develop that attitude. In the same way, the school atmosphere has an impact in school violence. Media is another misleading form of entertainment which develops violent behavior in children [12].

[13] Reported that most cases of violence faced by teachers remain unpublished so there is no accurate statistics of teachers who have been exposed to violence. The report revealed that $51 \%$ of reported violence was teacher violence against students, while in second rank came the students violence towards each other reached $27 \%$ and in the third rank came the teachers violence towards each other by $11 \%$ and in the fourth rank of student violence against teachers came by $8 \%$ and in the fifth and last came the student violence against the contents of the school by $3 \%$ of reported violence.

Violence against teachers, whether physical, verbal, emotional, direct or indirect, leaves a deep mark on selfconfidence and self-esteem of teachers, so it can be assumed that it hinders their work and affects their job satisfaction and performance, makes it difficult to create a healthy atmosphere in the classroom, and all this combined has an impact on final development and success of students. So greater understanding of teacher violence will have benefits to both teachers and students. In order to effectively intervene in schools, it is critical to gain a better understanding of the frequency and types of violence directed against teachers in order to develop appropriate prevention and 
intervention programs. The present study aims to assess frequency and causes of school-based violence and suggest school-based violence prevention guidelines.

The aim of the study is to assess frequency and causes of school-based violence among teachers at governmental preparatory schools and to develop school-based violence prevention guidelines among teachers at governmental preparatory schools.

\subsection{Research design}

\section{Subjects and Methods}

A descriptive correlational research design was utilized in this study. This design examines variables in their natural environments, find out what is happening, generate new insights, ask questions, assess phenomena in new light, generate ideas, seek to give an accurate profile of people, events and situations and display the relationships among variables [14].

\subsection{Setting}

Cairo governorate is divided into four directions; North, South, East and West, by using simple random sample technique, one direction was selected from these four directions. This direction was the "South". There are thirty two (32) educational directorates at Cairo Governorate; one directorate from the South of Cairo was selected randomly. This directorate was EL-Sayeda Zeinab educational directorate. All governmental preparatory schools for boys from this directorate were included; El helmia El kadima preparatory school, Mohamed Ali preparatory school, Elmahad Elolmy preparatory school, El monera preparatory school, Om Elmoamnen preparatory school and El gameya El khairia preparatory school. EL-Sayeda Zeinab district is an old one with large number of population about 149661, people in this area are considered as having an average socioeconomic standard [15].

\subsection{Sample}

A convenient sample of all teachers in preparatory schools for boys at EL-Sayeda Zeinab educational directorate (6 schools) was included in this study. Total preparatory school teachers at Cairo Governorate were around 260 teachers; each school had around 40 to 45 teachers. The total number of the sample was 228 males \& female teachers. The inclusion criteria are teachers exposed to violence in school.

\subsection{Tools for data collection:}

School teacher' structured interviewing tool was developed by the researcher after extensive review of the related literature. This tool had two parts:

Part I. Teacher's personal and work data: it includes teacher's age, education level, gender, marital status, job category and duration of work at school (4 questions).

Part II. School-based violence data: it included the following; 1. types of violence, source of violence, frequency of exposure to violence and occurrence of injury. 2. Causes of violence: divided into 3 parts A) inside schools as student get rid of repression, empty the frustration, poor communication between teacher and students, lack of academic advising and academic failure (10 question). B) Outside school as family disputes, aggressive parents, low economic level and education level of parents (8 questions). C) School work environment as inability of school administration to deal with student problems, lack of academic and social counseling to students, repression of the students inside the classroom and overcrowding at class room (6 questions). Scoring system; those who answered Yes got (2) and who answered No got (1).

Tool validity

Tools were submitted to a panel of five experts in the field of community health nursing and school health to test the content validity. Modifications were carried out accordingly.

\subsection{Ethical Consideration:}

Each teacher was informed about the purpose of the study and its importance. Researcher emphasized that, participation in the study was entirely voluntary. Anonymity and confidentiality were also assured and an informed verbal consent was obtained from teachers. All clients were informed that they can withdraw anytime without any penalty.

\subsection{Pilot Study}

A sample of $10 \%$ of the subjects who met the criteria of selection was included in the pilot study in order to assess the feasibility and the clarity of the tool and determine the needed time to answer the questions. Based on its result, minimal changes were carried out. Pilot study revealed that the average length of time needed to complete the questionnaire by teachers was approximately 30 minutes. 


\subsection{Procedure}

An official permission was obtained from Educational Directorate and Educational Department at Cairo Governorate to conduct the study. Also official permissions were obtained from the directors of the six selected schools then from the schools' teachers, who were exposed to violence and agreed to participate in the study. Data was collected through a period of 6 months from October 2014 to March 2015, two days/week from $9.00 \mathrm{am}$ to $12.00 \mathrm{pm}$.

Data was collected through distributing questionnaire to teachers. Based on the results, school-based violence prevention guidelines were developed by the researcher after extensive review of related literature. These developed guidelines were distributed to school directors, teachers, school nurses, social workers and a copy was left in the school library after conduction of the study.

\section{Description of guidelines:}

School-based violence prevention guidelines were developed based on Teacher Negotiation Committee, (TNC, $2011 \& 2012$ ) for tackling violence against staff in schools.

The developed guidelines included the following:

\section{1- The nature of violence includes:}

Types of violence: violence against teachers include; physical, verbal social and electronic. Physical violence involves; potential risk of harm and consequences of which may or may not be visible. Verbal violence; is the use of inappropriate and harsh words to hurt teacher. Social violence; includes saying untruths in order to undermine his dignity and expressed by ignoring, avoiding and refusing collaboration. Electronic violence; is damage the reputation, status and dignity of the teacher by using electronic devices as mobile phones, internet and popular social network.

Causes of violence: A) Inside schools; as overcrowded classes, get rid of repression conflict in teacher-student relationships, lack of academic advising, academic failure, inability to build friendship, imitation of others, time pressure inefficient student activity, culture diversity, direct others attention, negative competition between students, frustration and aggression. B) Outside school causes; as large family size, aggressive parents and absence of a parent, low economic level and education level of parents and aggressiveness from their parents. C) School work environment causes; absence of trained security man, insufficiency of corrective actions from school administration, absence of legal actions for affected teacher and unlock school gate are causes of violence.

\section{2- Assessing the risk for violence:}

Areas to consider include:

- Physical aspects include the design of the building and how it could be improved to reduce the likelihood of incidents of violence.

- Work practices and patterns include risk assessment identified particular jobs or activities that have potential for violence (perceived and actual risks and hazards).

3- Effect of violence: violence can lead to:

- Stress related absences.

- $\quad$ Poor morale.

- Impaired performance.

- a poor image for the school/college.

- Making it difficult to recruit and retain staff.

- $\quad$ Extra cost and increased absenteeism.

- Pain and distress.

\section{4- Roles and Responsibilities:}

The Board of Governors is responsible for:

- Introducing reasonable and appropriate procedures to protect teachers from violence in the school.

- $\quad$ Providing welfare support to teachers who experience violence at work.

- $\quad$ Ensuring that teachers are encouraged to record and report violent incidents.

\section{The Principal is responsible for:}

- $\quad$ Ensuring that all teachers are encouraged and aware of their responsibility to report incidents of violence and to cooperate with any investigation.

- $\quad$ Recording reported incidents of violence against staff and reporting these to the Governors.

- $\quad$ Encouraging all visitors to the school to be courteous and to comply with school rules, policies and procedures.

The Teacher is responsible for:

- $\quad$ Promoting and maintaining harmonious working relationships within the school.

- Identify health and safety problems.

- $\quad$ Assess and priorities the need for action.

- $\quad$ Suggest options available to eliminate or reduce risks and their relative merit;

- $\quad$ Evaluate their effectiveness. 
- $\quad$ Promote and communicate safety and health improvements and good practices.

- $\quad$ Reporting incidents when they occur to the Principal.

- $\quad$ Co-operating with any investigation following an incident.

- $\quad$ Co-operating with any measures to improve safety in the school.

5- Actions if violence occurs:

- $\quad$ Record the incident and report it to your Principal.

- $\quad$ Cooperate with any investigation.

- Consider the outcome of any risk assessment and work towards the implementation of any recommendations.

\subsection{Statistical Analysis}

Data were analyzed using Statistical Package for Social Science (SPSS windows) version 20. Numerical data were expressed as mean $\pm \mathrm{SD}$, and range. Relations between different numerical variables were tested using Pearson correlation. Probability (p-value) less than 0.05 was considered significant and less than 0.001 was considered as highly significant.

\section{Results}

The study results were presented in three main parts: 1) Personal and work data of the teacher 2) Schoolbased violence data and 3) Relation of school-based violence causes and frequency of exposure.

Results revealed that, $76.3 \%$ of the teachers were males. As for the teachers' age, $68 \%$ of the teachers were 25 to less than 45 years old, while $32 \%$ were 45 years to less than 55 years old with a mean age $39.79 \pm 6.9$ years. All teachers were married. Regarding work duration, results revealed that teachers worked from 1 year to 29 years with a mean $13.92 \pm 6.97$ years.

Results indicates that, $52.6 \%$ of the teachers were exposed to verbal violence, $38.2 \%$ of them had both physical and verbal violence and only $9.2 \%$ were exposed to physical violence. In relation to the frequency of violence, more than two third (67.1\%) of teachers were exposed to violence less than five times while $32.9 \%$ were exposed to violence five times. Regarding source of violence, figure (1) revealed that, $64.9 \%$ of the teachers were exposed to violence by students, $19.7 \%$ of teachers were exposed to violence from student's parents and $15.4 \%$ of them were exposed to violence from both the students and their parents. Only $13.6 \%$ of teachers reported being exposed to physical injury and $33.8 \%$ of them reported officially their exposure to violence after being exposed to violence. Table (1) indicates that, there are many causes which contribute to the onset of school violence; regarding to the causes inside schools, teachers reported that, $87.3 \%$ of the students may develop a violent behavior in school as a result of overcrowded classes and repression release, while $85.5 \%, 81.6 \%$ and $80.3 \%$ of teachers indicated that, conflict in teacher-student relationships, lack of academic advising and academic failure respectively are causes of violence inside schools. Other causes of violence included inability to build friendship (79.4\%), imitation of other children or adult (78.9\%), time pressure (77.6\%) and inefficient student's activities (76.3\%).

In relation to outside school causes of violence; most of the teachers revealed that, large family size $(95.2 \%)$, aggressive parents $(92.1 \%)$ and absence of one of the parents $(89.0 \%)$ are causes of violent behavior from students and while $86.8 \%$ and $85.1 \%$ of teachers respectively reported that, low economic level and education level of student's parents are the causes of violence (Table 2). As for school work environment causes for violence, $82 \%$ of teachers revealed that, absence of trained security person is the first cause of exposure to violence while $73.2 \%$ reported that insufficiency of corrective actions from school administration, absence of legal actions for affected teacher (72.8\%) and unlocked school gate $(71.1 \%)$ are the main causes of violence (Table 3).

The results indicates a highly statistically significant relation between frequency of violence against teachers from student as a result of overcrowded classes ( $p<0.001)$, lack of academic advising ( $p<0.001)$ and to get rid of repression $(\mathrm{p}<0.001)$. Also a statistically significant relation was found between inability to build friendship $(\mathrm{p}<0.05)$, conflict in teacher-student relationships $(\mathrm{p}<0.05)$, time pressure $(\mathrm{p}<0.02)$ and inactive of student activities $(\mathrm{p}<0.05)$. While lack of administrative supports and leave school gate open as causes of violence related to school environmental were highly statistically significant $(\mathrm{p}<0.000$ and 0.004 respectively) with frequency of violence against teachers (Table 4). Regarding to outside school causes; family disputes $(p<0.004)$, low economic level of parent $(p<0.004)$, low education level of parent $(<0.001)$ and absence of a parent $(p<0.001)$ were statistically significant with frequency of violence against teachers (Table 5). 


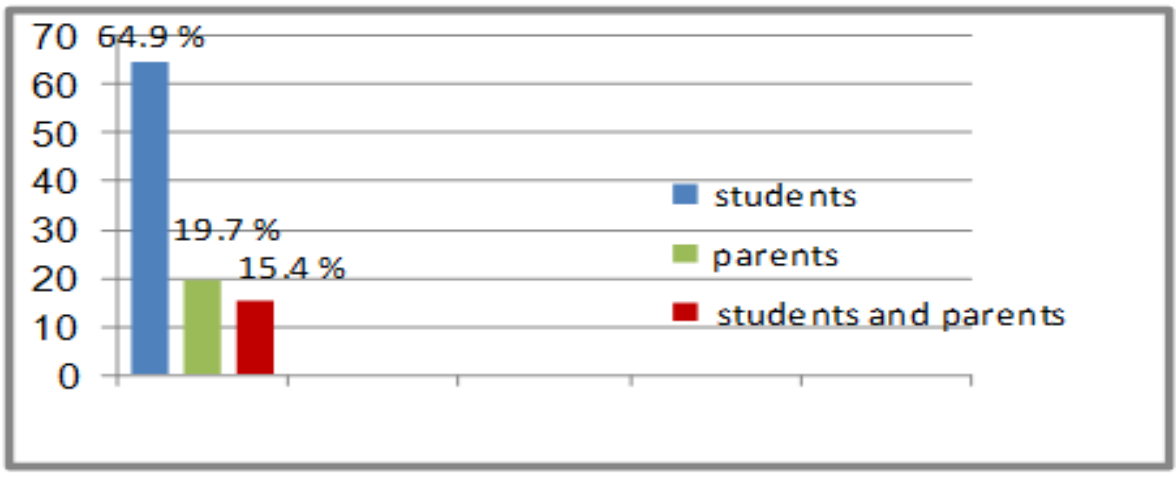

Figure 1: Source of violence

Table (1): Distribution of the teachers as regards to causes of violence inside schools $(\mathbf{n}=\mathbf{2 2 8})$

\begin{tabular}{|c|c|c|c|c|}
\hline Inside school causes & Yes & $\%$ & No & $\%$ \\
\hline Overcrowded classes & 199 & 87.3 & 29 & 12.7 \\
\hline Get rid of repression & 199 & 87.3 & 29 & 12.7 \\
\hline Conflict in teacher-student relationships & 195 & 85.5 & 33 & 14.5 \\
\hline Lack of academic advising & 186 & 81.6 & 42 & 18.4 \\
\hline Academic failure & 183 & 80.3 & 45 & 19.7 \\
\hline Inability to build friendship & 181 & 79.4 & 47 & 20.6 \\
\hline Imitation of other children or parents & 180 & 78.9 & 48 & 21.1 \\
\hline Time pressure & 177 & 77.6 & 51 & 22.4 \\
\hline Inactive of student activities & 174 & 76.3 & 54 & 23.7 \\
\hline Direct others attention & 161 & 70.6 & 67 & 29.4 \\
\hline Culture diversity & 156 & 68.4 & 72 & 31.6 \\
\hline
\end{tabular}

* Responses are not mutually exclusive

Table (2): Distribution of the teachers as regards to causes of violence outside school $(n=228)$

\begin{tabular}{|c|c|c|c|c|}
\hline Outside school causes & Yes & $\%$ & No & $\%$ \\
\hline Large family size & 217 & 95.2 & 11 & 4.8 \\
\hline Aggressive parents & 210 & 92.1 & 18 & 7.9 \\
\hline Absence of a parent & 203 & 89.0 & 25 & 11.0 \\
\hline Low economic level of parent & 198 & 86.8 & 30 & 13.2 \\
\hline Low education level of parent & 194 & 85.1 & 34 & 14.9 \\
\hline
\end{tabular}

* Responses are not mutually exclusive

Table (3): Distribution of the teachers as regards to causes of violence related to school environmental $(n=228)$

\begin{tabular}{|c|c|c|c|c|}
\hline School environment causes & Yes & $\%$ & No & $\%$ \\
\hline Absence of trained security man & 187 & 82.0 & 41 & 18.0 \\
\hline Lack of administrative supports & 167 & 73.2 & 61 & 26.8 \\
\hline Absence of legal actions for affected teacher & 166 & 72.8 & 62 & 27.2 \\
\hline Leave school gate open & 162 & 71.1 & 66 & 28.9 \\
\hline
\end{tabular}

* Responses are not mutually exclusive

Table (4): Relation of frequency of exposure to violence and causes of violence inside school

\begin{tabular}{|l|c|c|}
\hline \multicolumn{1}{|c|}{ Item } & $\chi 2$ & P \\
\hline Overcrowded classes & 7.731 & 0.005 \\
\hline Lack of academic advising & 12.739 & 0.001 \\
\hline Get rid of repression & 13.837 & 0.001 \\
\hline Inability to build friendship & 3.620 & 0.05 \\
\hline Conflict in teacher-student relationships & 3.784 & 0.05 \\
\hline Time pressure & 5.254 & 0.02 \\
\hline Inactive of student activities & 3.651 & 0.05 \\
\hline Lack of administrative supports & 20.060 & 0.000 \\
\hline Leave school gate open & 8.336 & 0.004 \\
\hline
\end{tabular}


Table ( 5): Relation of frequency of exposure to violence and causes of violence outside schools

\begin{tabular}{|l|c|c|}
\hline \multicolumn{1}{|c|}{ Item } & $\chi^{2}$ & P \\
\hline Family disputes & 8.307 & 0.004 \\
\hline Low economic level of parent & 8.203 & 0.004 \\
\hline Low education level of parent & 19.588 & 0.001 \\
\hline Absence of a parent & 10.620 & 0.001 \\
\hline
\end{tabular}

\section{Discussion}

Violence against teachers is a significant but under investigated problem that has profound implications for schooling, teacher retention, and overall student performance [16].

Results revealed that, above three quarters of the teachers were males. In agreement with the study results [16] who examined violence directed toward teachers in the United State of America found that, male teachers were associated with a higher percentage of victimization. Also the study done by [8] on Brazilian teachers revealed that, threat and injury were highest among male teachers. This could be related to the sample selection where teachers were selected from preparatory schools for boys and most of them were males.

The results of the current study indicated that, more than half of the teachers were exposed to verbal violence; few numbers were exposed to physical violence and more than one third of teachers reported being exposed to both physical and verbal violence. In the same line the study conducted in Slovakia by [16] on 364 teachers showed that, teachers were exposed to violence from students in the form of verbal violence (35.4\%) and (4.9\%) physical violence. This could be related to absence of legislation and polices that could punish students for committing such violence against teachers or any person in the school.

Results revealed that, around two thirds of teachers were exposed to violence by students and few were exposed to violence by parents. Regarding frequency of violence, more than two thirds of teachers were exposed to violence less than five times while one third reported exposure to violence five times. Similar result was found by [17] who examined violence directed against teachers and found that, $80 \%$ of teachers reported at least one victimization experience in the current or past year, and of those who experienced an offense, $94 \%$ reported being victimized by students. Also the study done by [18] to explore non-experimental teacher training in school violence, and the effects of such training on teacher outcomes in the United States found that, $48 \%$ of teachers reported being victimized by students, approximately $19 \%$ were victimized by parents, and approximately $11 \%$ experienced victimization by colleagues.

Regarding the causes of school-based violence, most teachers reported that, overcrowded classes and repression release were causes of violence from students. A statistically significant relation was found between frequency of violence occurrences against teachers and overcrowded classes and repression release. In accordance with the study results done by [19] that studied high school teachers in South African and found that, $57.7 \%$ of the participants reported that overcrowded classes contributed to the frequency of school violence because overcrowded classes are difficult to control and learners tend to misbehave without being detected. This also applied to the Egyptian schools where the classes may be over 40 students with poor ventilation which can predispose to violence.

Concerning the causes of violence inside schools, results revealed that, the majority of the teachers indicated that, lack of academic advising for students, inability to build friendship, conflict in teacher-student relationships and time pressure are statistically significant related with frequency of violence. [5] Revealed that, academic advising to students used to resolve emotional, social or behavioral problems and help them develop a clearer focus or sense of direction. Further, increasing school resources, decreasing class sizes, and providing continual support, training and guidance for teachers may facilitate more positive classroom environments to create more supportive student-teacher relationships. In Egypt, teachers are overloaded with heavy teaching loads and administrative duties; therefore, they do not have the time to communicate with students nicely or look into their problems and try to solve them.

Regarding to outside school causes; large family size, low economic level of parent, low education level of parents and absence of a parents were highly statistically significant with frequency occurrence of violence against teachers. The study done by [20] in U. S. A. revealed that, students who were living in larger families may have a higher likelihood of experiencing violence from other siblings or parents and transfer the home adjusted pattern into the school environment. Also students who have multiple siblings are less likely to succeed academically, have less social support, and are more likely to maintain a pessimistic attitude towards the learning environment. Also [18] who studied the relationship between teachers training, perceptions of school violence, and burnout in U. S. A. found that, $56.3 \%$ and $26.6 \%$ of teachers respectively identified that family problems and poverty as major contributing factors to the frequent occurrence of school violence.

A highly statistically significant difference was found between the occurrence of violence toward teachers and causes of violence related to school environmental as leaving school gate open and lack of administrative supports. The study done by [21] in Turkey revealed that, insecure school atmosphere would adversely affect the quality of education because being subjected to violence would lead to negative attitudes towards the school and cause 
loss of motivation. This may be related to disorganized school structures, negative school climates and lack of administrative and social supports.

\section{Conclusion}

The study concluded that, the common causes of violence against teachers identified were; overcrowded classes, repression release, conflict in teacher-student relationships, large family size, aggressive parents and absence of a parent. Regarding to school environment causes of violence included absence of trained security person, lack of administrative supports and absence of legal actions for affected teacher.

\section{Recommendation}

Based on the findings of the present research the following recommendations are suggested; in depth studies need to be carried out to assess causes and implications of violence against teachers. Further studies are needed to assess prevalence; predictors and consequences of violence directed against teachers and these studies should be conducted with nationally representative samples. Increase awareness around violence directed at teachers and to promote a national commitment to the study of this phenomenon.

\section{References}

[1] Espelage, D., Anderman, E., Brown, V., Jones, A., Lane, k., McMahon, S., Reddy, L., Reynolds, L., (2013). Understanding and Preventing Violence Directed Against Teachers. American Psychological Association; 68 (2) 75-87.

[2] Ez-Elarab, H.S., S.M. Sabbour, M.A. Gadallah and T.A. Asaad, 2007. Prevalence and Risk Factors of Violence Among Elementary School Children in Cairo. Journal of Egypt Public Health Assoc., 82(1-2): 172-146.

[3] National Institute of Occupational Safety and Health (NIOSH). (2013). Occupational Violence and Homicide; Pub. No.155.

[4] World Health Organization (2013). Definition and Typology of Violence. Violence prevention alliance.

Retrieved from http://www.who.int/violenceprevention/approach/definition/en/index.html

[5] Alzyoud M., Al-Ali A. \& Bin Tareef, O. (2016). Violence against Teachers in Jordanian Schools. European Scientific Journal; 12, (10).

[6] Espelage, D. L., \& De La Rue, L. (2011). Getting serious about community-based approaches to youth violence prevention. Progress in Community Health Partnerships: Research, Education, and Action, 5(1), 3-5.

[7] Lokmić, M. Opić, S. \& Bilić, V. (2013). Violence against Teachers- Rule or Exception. International Journal of Cognitive Research in science, Engineering and Education; 1(2).

[8] Soares M. \& Machado L. (2014). Violence Against Teachers:. Problems of Education in the 21st century. Research, Education, and Action; 58(144).

[9] Tuck, C., Cagginello, J. \& Rose, K. (2013). School violence, Role of the School Nurse in Prevention. Position statement. National Association of School Nurses; Retrieved from:www.nasn.org/PolicyAdvocacy/PositionPapersandReports/NASNPositionStatements.

[10] King, K. (2014). Violence in the School Setting: A School Nurse Perspective. ANA Periodicals; 19(1).

[11] Jacobson, G., Riesch, S. K., Temkin, B. M., Kedrowski, K. M., \& Kluba, N. (2011). Students Feeling Unsafe in School: Fifth Graders' Experiences. The Journal of School Nursing; 27, 2, 149-159.

[12] Share, H. M., El-Shair, E.H. and Ismail, M, G. (2013). Assessment of Violence among Primary School Children at Cairo Governorate. Middle-East Journal of Scientific Research; 16 (2): 179-190.

[13] Teachers Rights Watch. (2015).Teachers Association Almstqlh- Egypt.

[14] Nandhini \& Rangarjan (2013). A Playbook for Research Methods: Integrating Conceptual frameworks and Project Management. Available at: http//www.open library.com.

[15] The Ministry of State for Administrative Development. (2014). General Directorate for Information and Documentation; online portal for Cairo Governorate.

[16] McMahon, S. D., Martinez, A., Espelage, D., Reddy, L. A., Rose, C.,Lane, K.,...Brown, V. (2014). Violence Directed against Teachers: Results from a National Survey. Psychology in the Schools; 51(7).

[17] Ozdemir, S. M. (2012). An investigation of Violence against Teachers in Turkey. Journal of Instructional Psychology; 39(1), 51-62.

[18] Geissler, K, L.(2015). The relationship between teacher training, perceptions of school violence, and burnout. A dissertation, Faculty in Educational Psychology; NEW YORK.

[19] Mncube V., \& Harber C. (2013). The Dynamics of Violence in South African schools, Teaching and Teacher Education; 28, $1059-$ 1068 .

[20] Garnett, V. (2014). The Effects of Violence on Academic Progress and Classroom Behavior: From a Parent's Perspective. VISTAS; 91.

[21] Sungu H. (2015). Teacher Victimization in Turkey: A Review of the News on Violence against Teachers; 20 (3), 694-706. Teachers Rights Watch, 2015.Teachers Association Almstqlh- Egypt. 